\title{
O CURSO TÉCNICO EM MEIO AMBIENTE INTEGRADO AO ENSINO MÉDIO NO ESTADO DO PARANÁ COMO ALTERNATIVA PARA A FORMAÇÃO INTEGRAL DOS JOVENS
}

\author{
Ana Paula da Silva Rodrigues*, Eloy Fassi Casagrande Junior, Marcia Regina Rodrigues da \\ Silva Zago, Maclovia Corrêa da Silva \\ *E-mail: anageografia.smed@gmail.com \\ Universidade Tecnológica Federal do Paraná \\ DOI: $10.15628 /$ rbept.2020.9094
}

Artigo submetido em out/2019 e aceito em fev/2020

\begin{abstract}
RESUMO
O presente artigo aborda a regulamentação da Educação Profissional Técnica de Nível Médio por meio da análise da organização do Curso Técnico de Meio Ambiente Integrado ao Ensino Médio no Estado do Paraná. A intensificação nos processos produtivos, associada ao desenvolvimento tecnológico, agravou a degradação ambiental, implicando uma nova forma de relação da sociedade com a natureza. Desse modo, a formação articula conhecimentos científicos com a qualificação profissional, abrangendo a relação entre educação e trabalho, pressupostos da educação politécnica. Constata-se a relevância social do Curso, considerando-o enquanto uma possibilidade para a formação de profissionais preocupados com a realidade socioambiental da atualidade, com a proteção ambiental e com a gestão dos recursos naturais.
\end{abstract}

Palavras-chave: Educação. Qualificação Profissional. Técnico em Meio Ambiente.

\section{THE TECHNICAL COURSE IN ENVIRONMENT INTEGRATED WITH HIGH SCHOOL IN THE STATE OF PARANÁ AS AN ALTERNATIVE FOR THE YOUNG PEOPLE'S INTEGRAL FORMATION}

\begin{abstract}
This article deals with the regulation of High School Technical Vocational Education through the analysis of the organization of the Technical Course of Environment Integrated to High School in the State of Paraná. The intensification in production processes, associated with technological development has aggravated environmental degradation, implying a new form of relationship between society and nature. Thus, training links scientific knowledge with professional qualification, covering the relationship between education and work, assumptions of polytechnic education. The social relevance of the course is considered, as a possibility for the formation of professionals concerned with the current social and environmental reality, with environmental protection and with the management of natural resources.
\end{abstract}

Keywords: Education. Professional qualification. Environmental technician. 


\section{INTRODUÇÃO}

Educação e trabalho constituem-se como pilares de um ensino capaz de promover a formação integral do ser humano para sua vida em sociedade. Essas dimensões da vida, entretanto, foram separadas com a consolidação do modo de produção capitalista, e seus interesses de dominação, o que inclui a dominação da natureza (GUIMARÃES, 2012; CARVALHO, 1998). Essa dominação expressa, para Guimarães (2012, p. 33), relação com a sociedade moderna em que o crescimento econômico encontra-se fundamentado "[...] na extração ilimitada de recursos naturais, renováveis ou não, na acumulação contínua de capitais, na produção ampliada de bens, sem considerar as interações entre essas intervenções e o ambiente". A escola, nessa configuração social, objetiva apenas a formação para o mundo do trabalho, segundo Enguita (1989).

O processo de formação dos jovens para a inserção no mercado de trabalho, tendo em vista que a sobrevivência se encontra a ele atrelada, especialmente no caso das camadas populares, apresenta estreita relação com a formação adquirida na etapa de ensino correspondente ao Ensino Médio. Desse modo, a educação profissional técnica de nível médio, considerando cursos que articulem conhecimentos científicos e de qualificação profissional de maneira integrada, caracteriza-se como possibilidade formativa de uma educação mais humana e transformadora da realidade em suas múltiplas esferas (FRIGOTTO et al., 2005; MOURA et al., 2015; SAVIANI, 2007).

O presente artigo aborda a intrínseca relação entre conhecimento científico e qualificação profissional. Apresenta-se a legislação educacional e ambiental que evidenciam a obrigatoriedade de inserção de conhecimentos relativos à Educação Ambiental (EA) no processo de escolarização, tendo em vista o crescente processo de produção e o desenvolvimento de tecnologias com potencial destruidor do meio ambiente e da qualidade de vida. Retrata-se a regulamentação e organização do Curso Técnico em Meio Ambiente Integrado ao Ensino Médio no Estado do Paraná, considerando-o como uma alternativa para contribuir com a formação integral dos jovens, associada com a preocupação inerente às questões ambientais, tão essenciais em nosso tempo.

\section{EDUCAÇÃO FORMAL E TRABALHO}

A transformação da estrutura do trabalho ao longo dos tempos, desde 0 trabalho do artesão, com o domínio do conhecimento do processo produtivo do artefato produzido do início ao fim, até a sua fragmentação, característica dos processos produtivos relativos ao modo de produção capitalista e a industrialização, a sociedade, de modo geral, passou por profundas reformulações. Nesse contexto insere-se também a escola e, consequentemente a educação formal, que na atualidade, de acordo com 
Enguita $^{1}$ (1989, p. 231), “[...] Durante alguns poucos anos, [...] deve qualificar os futuros trabalhadores para toda sua vida".

Trabalho é uma atividade inerentemente humana, tornando-se relevante que o trabalhador adquira, no decorrer do seu processo formativo, ou de qualificação, a compreensão do trabalho que realiza, assim como da realidade em que se encontra inserido. Saviani (2007, p. 154) esclarece que trabalho é "o ato de agir sobre a natureza transformando-a em função das necessidades humanas". Nesse sentido, Carvalho (1998), salienta que por meio do trabalho, juntamente com o desenvolvimento tecnológico e de técnicas para atender aos seus objetivos é que os seres humanos encontraram formas para dominar a natureza. Já para Gramsci, o trabalho constitui-se como um "princípio educativo fundamental", de acordo com o exposto por Moura, et al. (2015). Segundo esses autores, como alternativa para a forma como a escola tradicional encontra-se organizada, e com vistas à formação humana, Gramsci propõe a escola unitária, objetivando a "integração entre trabalho, ciência e cultura".

A dualidade no ensino destinado aos jovens, estratégia utilizada de modo a evitar que as camadas populares ascendessem ao Ensino Superior, ou seja, o ensino concebido em educação geral e educação profissional, no que se refere ao Ensino Médio, reflete os interesses de uma sociedade organizada em classes, ressaltando as contradições características do modo de produção capitalista (MOURA, et al., 2015). Nessa conjuntura, a educação politécnica, apresenta-se como uma possibilidade de superação da dicotomia no sistema de ensino, com vistas à reunificação do ensino com a qualificação profissional. O conceito de politecnia, educação politécnica ou tecnológica pode ser concebido, portanto, como uma forma de educação integral do ser humano, pretendendo-se a constituição de uma sociedade mais justa e igualitária.

A concepção de educação politécnica para Saviani (2007, p. 161), é uma concepção diferenciada da apresentada pelo Ensino Médio organizado em cursos profissionalizantes, significando a "especialização como domínio dos fundamentos científicos das diferentes técnicas utilizadas na produção moderna". Partindo da abordagem marxista acerca do conceito de politecnia, Saviani considera que "implica a união entre escola e trabalho ou, mais especificamente, entre instrução intelectual e trabalho produtivo" (SAVIANI, 2007, p. 162).

Em relação às terminologias ou expressões utilizadas, educação politécnica ou tecnológica, Saviani (2007, p. 162-163), recorre aos estudos realizados por Manacorda, salientando que para esse autor, a utilização da expressão "educação tecnológica" seria mais representativa do termo politecnia, em função da análise detalhada das obras de Marx feitas por ele. Saviani, todavia, salienta que ambas, educação tecnológica ou politecnia, são representativas do "mesmo conteúdo", e acrescenta que, mesmo sem desconsiderar tais estudos, entende que "podem ser considerados sinônimos".

\footnotetext{
${ }^{1}$ Nesse texto, o autor parte da premissa de que os processos preparatórios que visavam à integração nas relações sociais de produção sempre existiram, demonstrando, por meio de uma análise histórica, como a construção das escolas esteve atrelada às relações de produção capitalista.
} 
De acordo com o exposto, o processo educativo realizado no Ensino Médio Integrado com a educação profissional, tendo como pressuposto a educação politécnica, deve ser capaz de propiciar a formação integral dos estudantes. Isso significa não apenas qualificar os jovens para o trabalho produtivo, mas para que compreendam a sociedade em que vivem em suas múltiplas dimensões: políticas, econômicas, sociais, ambientais, tecnológicas e culturais, apropriando-se de conhecimentos que os fundamentem para uma atuação consciente e transformadora. Conforme salientam Frigotto, et al.,

\begin{abstract}
O ideário da Politecnia buscava e busca romper com a dicotomia entre educação básica e técnica, resgatando o princípio da formação humana em sua totalidade; em termos epistemológicos e pedagógicos, esse ideário defendia um ensino que integrasse ciência e cultura, humanismo e tecnologia, visando ao desenvolvimento de todas as potencialidades humanas. Por essa perspectiva, o objetivo profissionalizante não teria fim em si mesmo nem se pautaria pelos interesses do mercado, mas constituir-se-ia numa possibilidade a mais para os estudantes na construção de seus projetos de vida, socialmente determinados, possibilitados por uma formação ampla e integral (FRIGOTTO, et al., 2005, p. 10).
\end{abstract}

Uma educação para todos, nos moldes da escola unitária proposta por Gramsci, e de uma educação politécnica, conforme enfatiza Saviani, detêm uma abordagem ampla, totalizante e transformadora. A perspectiva defendida, almejando-se a reunificação do ensino com o trabalho, de acordo com Moura, et al. (2015), ainda se configura em projeto futuro. Esses autores indicam um caminho possível, sinalizando que "o ensino médio integrado pode ser a gênese dessa formação", aspecto também demonstrado por Frigotto, et al. (2005, p. 43), ao considerar que "o ensino médio integrado ao ensino técnico, sob uma base unitária de formação geral, é uma condição necessária para se fazer a "travessia" para uma nova realidade".

De acordo com os autores que embasam o estudo, observa-se a pertinência e necessidade de escolas profissionais que abranjam a realidade em que os estudantes vivem, além das implicações humanas e sociais inerentes ao mundo técnico e ao universo do trabalho. Assim, um currículo integrado deve garantir que o ser humano possa "apreender as contradições das relações sociais de produção e produzir sua existência com o seu trabalho" (CIAVATTA; RAMOS, 2012, p. 25).

\title{
3 A OBRIGATORIEDADE DA ABORDAGEM AMBIENTAL
}

O conceito de trabalho, anteriormente apresentado e proposto por Saviani (2007), demonstra que a sobrevivência do ser humano está condicionada à interferência que realiza sobre a natureza. Ocorre que essa ação, especialmente com a intensificação dos processos produtivos a partir da Revolução Industrial, e mais intensamente com a Modernidade, em que a "idéia de progresso, [...] idéia tipicamente moderna", conforme ressalta Pesavento 
(1997, p. 46), tem se demonstrado altamente destrutiva e degradadora da qualidade de vida e do meio ambiente.

Nessa conjuntura, ciência e técnica apresentam-se enquanto conhecimento organizado, fornecendo sustentação para uma visão de mundo em que a ideia de "progresso" encontra-se atrelada à exploração dos recursos naturais para abastecer a indústria. Desse modo, a crescente produção de mercadorias visa, em última instância, a criação de necessidades que até então eram inexistentes, levando ao aumento do consumo e consequentemente do lucro, gerando cada vez mais o acúmulo de capital (PESAVENTO, 1997), e produzindo "uma também crescente desigualdade social, tanto em nível nacional quanto mundial” (GUIMARÃES, 2015, p. 50).

Sendo assim, o consumo exacerbado, característico da forma como a sociedade encontra-se organizada, tem colocado em risco todos os recursos naturais, bem como todas as formas de vida existentes no planeta. Rachel Carson, importante bióloga e escritora norte-americana, já alertava no livro "Silent Spring" - "Primavera Silenciosa" - publicado em 1962, os efeitos destrutivos que tecnologias utilizadas de maneira indiscriminada apresentavam para o meio ambiente humano, sendo ignorados pelos grandes fabricantes, assim como pelo poder público, acarretando graves consequências para a saúde humana e para as demais formas de vida ${ }^{2}$.

Desde Carson os debates acerca do meio ambiente intensificaram-se no mundo todo. Inúmeros Congressos, Seminários e Conferências foram realizados para abordar a temática ambiental, como a Conferência das Nações Unidas sobre o Meio Ambiente Humano, realizada pela Organização Nacional das Nações Unidas (ONU), em 1972 em Estocolmo, na Suécia. ${ }^{3}$

Todos esses eventos, com repercussão mundial, colocaram em pauta as questões ambientais e a relevância da problemática na atualidade, inserindo a temática nos debates em busca de alternativas para solucionar a "crise ambiental" vivenciada (GUIMARÃES, 2015). Nesse contexto, as consequências resultantes do processo produtivo evidenciam, de acordo com Santos (2000), um "estilo de desenvolvimento predatório" dos recursos naturais em escala

\footnotetext{
${ }^{2}$ Carson abordava os efeitos nocivos em relação aos fertilizantes químicos (pesticidas, inseticidas e herbicidas), ou "biocidas", como a própria autora os chamou, em todo o ecossistema. Por meio de estudos científicos, na maioria dos seus exemplos, demonstrou como essas substâncias entram em toda a cadeia alimentar, contaminando o meio ambiente e, assim, atingindo todas as formas de vida, não apenas àquelas em que o uso inicial destinavase.

${ }^{3} \mathrm{~A}$ esses se seguiram vários outros eventos de importância mundial, como a primeira Conferência Intergovernamental sobre Educação Ambiental realizada em 1977 em Tbilisi. Uma década depois, em 1987, observa-se a publicação do Relatório Brundtland ou "Nosso Futuro Comum", em que o desenvolvimento sustentável foi retratado como aquele capaz de garantir as necessidades atuais sem comprometer os recursos naturais para atender as necessidades das gerações futuras. Já no Brasil, a realização da Conferência das Nações Unidas sobre Meio Ambiente e Desenvolvimento realizada na cidade do Rio de Janeiro em 1992, intitulada "Eco 92", também conhecida como "Rio 92", em que se elaborou a Agenda 21 "[...] um programa de alcance mundial para estabelecer determinadas diretrizes no processo de crescimento econômico e desenvolvimento social, fundamentados nos princípios da sustentabilidade" (BRUNACCI; PHILIPPI Jr, 2014, p. 313), caracterizam-se como alguns exemplos.
} 
global, sendo que "O objetivo maior da produção moderna é obter a máxima produtividade" (SANTOS, 2000, p. 26), e não a preservação do meio ambiente.

Guimarães (2015) destaca que nos últimos anos houve uma ampla divulgação acerca das informações sobre a importância e necessidade de preservação da natureza, aumentando o nível de conscientização da população, especialmente por meio da educação. Entretanto, esse considerável avanço ainda não se tornou suficiente para que o quadro de destruição, oriundo da "sociedade urbano-industrial", fosse reduzido.

No campo das políticas públicas, a implantação da Lei no 6.938/1981 Política Nacional do Meio Ambiente - (BRASIL, 1981), apresentando como objetivo a preservação, melhoria e recuperação da qualidade ambiental, tornou-se um referencial também para a educação escolar. $O$ inciso $X$ do art. $2^{\circ}$ enfatiza que a EA deve ser incluída em todos os níveis de ensino, demonstrando um passo importante no que concerne ao trabalho pedagógico com a dimensão ambiental nos espaços escolares. A promulgação da Constituição Federal (BRASIL, 1988), também pode ser considerada outro marco relevante, evidenciando-se no art. 2250 o direito de todos ao meio ambiente ecologicamente equilibrado.

Assim, o Brasil inicia sua trajetória para a implantação de políticas públicas voltadas para a EA e para a abordagem do meio ambiente no campo educativo. Ainda nesse viés, observam-se a implementação dos Parâmetros Curriculares Nacionais (BRASIL, 1997), considerando o meio ambiente como um dos temas que devem perpassar as Áreas de Conhecimento que compõem os currículos escolares, com abordagem transversal e interdisciplinar; a Política Nacional de EA (BRASIL, 1999), explicitando a obrigatoriedade da inserção da EA no âmbito formal de ensino, por meio de práticas interdisciplinares, não devendo configurar-se como disciplina específica; as Diretrizes Curriculares Nacionais para a EA (BRASIL, 2012), abordando as especificidades da prática pedagógica com a EA nos espaços escolares; e a mais recente, Base Nacional Comum Curricular (BRASIL, 2017), preconizando a imprescindibilidade de que as políticas anteriormente citadas sejam consideradas para a inclusão da EA nos currículos e/ou propostas pedagógicas dos Estados e municípios brasileiros.

Destaca-se que transversalidade, de acordo com os Parâmetros Curriculares Nacionais (BRASIL, 1997, p. 193), se expressa pela busca da "transformação dos conceitos, a explicitação de valores e a inclusão de procedimentos, sempre vinculados à realidade cotidiana da sociedade, de modo que obtenha cidadãos participantes"; e interdisciplinaridade sendo "[...] a interação das disciplinas científicas, de seus conceitos e diretrizes, de suas metodologias, de seus procedimentos, de seus dados e da organização de seu ensino" (FAZENDA, 2011, p. 34).

Ao modelo cartesiano de educação, ainda predominante, pode-se atribuir a fragmentação do trabalho com a EA na escola. Trabalho este que tem ocorrido em Áreas de Conhecimento que, em detrimento de suas respectivas naturezas e especificidades acabam apresentando maior proximidade com os conteúdos ambientais, como a Geografia e as Ciências Naturais, por exemplo. 
Nesta linha de pensamento, segundo Rodrigues (2018), encontram-se as políticas públicas educacionais e ambientais que, apesar da aparente integração em nível macro, distanciam-se no momento de sua efetivação, ou seja, na elaboração e cumprimento de diretrizes voltadas para as escolas pelos Estados e municípios.

\begin{abstract}
Assevera-se que o cartesianismo instituiu uma forma de apreensão do conhecimento por meio da fragmentação, conduzindo a problemas como o isolamento de ideias e a falta de conexão entre os saberes locais, regionais, nacionais e internacionais e a produção da ciência. O campo ambiental também foi contaminado por essa metodologia de estudo. Nessa lógica, Grün (2012) reforça a impossibilidade de a EA inserir-se dentro do paradigma cartesiano, no qual há um dualismo entre sujeito e objeto, e natureza e seres humanos, levando a uma "objetificação da natureza", resultantes do paradigma industrial capitalista que se encontra na gênese da crise ecológica da modernidade (RODRIGUES, 2018, p. 42).
\end{abstract}

A proteção ambiental, o que inclui conservação e preservação, requer um intensivo processo de mudanças de atitudes e comportamentos. A aquisição e consolidação de valores, saberes, conhecimentos e práticas socioambientais adequadas com esse tempo deve considerar a realidade dos estudantes. Para Guimarães (2015)

[...] A fragmentação e a simplificação que reduzem a compreensão da realidade, características essas do paradigma cientificistamecanicista que se consolidou a partir da Idade Moderna, vêm sendo analisado por vários autores como um dos pilares da crise ambiental da atualidade. Essas características não dão conta da compreensão da sociedade e do meio ambiente em sua relação, com uma realidade complexa (GUIMARÃES, 2015, p. 48).

Desta forma, configura-se como uma das responsabilidades da instituição escolar garantir, por meio de suas práticas pedagógicas, a sistematização dos conhecimentos ambientais, partindo da realidade vivenciada pelos estudantes e visando "fomentar a percepção da necessária integração do ser humano com a natureza" (GUIMARÃES, 2012, p. 35). Isso auxiliará na constituição de uma sociedade mais igualitária e ambientalmente sustentável para todos.

\title{
4 A BASE LEGAL dA EDUCAÇÃo PROFISSIONAL TÉCNICA DE NÍVEL MÉDIO
}

A universalização do ensino, o que significou a inserção daqueles que não pertenciam à camada privilegiada da sociedade e, portanto, se encontravam excluídos do processo de escolarização, acabou por reforçar as contradições no contexto de uma sociedade capitalista. Conforme demonstra 
Enguita (1989, p. 228), "as escolas geram nos jovens expectativas que o trabalho, com sua estrutura atual, não pode satisfazer".

A qualificação para o trabalho, retratada na antiga Lei de Diretrizes e Bases da Educação Nacional (LDB) - Lei no 5692/1971, responsável pela organização dos até então intitulados ensinos de $1^{\circ}$ e $2^{\circ}$ graus, obteve méritos pela integração do ensino profissionalizante ao sistema regular de ensino, contando com a garantia de continuidade dos estudos. Todavia, a dualidade entre formação científica e qualificação profissional, mais uma vez acentuou a divisão de classes. Salienta-se que a educação profissional, requerida especialmente por jovens que almejam (ou necessitam) inserir-se no mercado de trabalho de forma mais "rápida", antes do término da graduação, no caso daqueles que pretendem (ou terão acesso) a essa formação, é também um aspecto que evidencia a desigualdade social.

A educação pública, como dever do Estado e direito de todas as

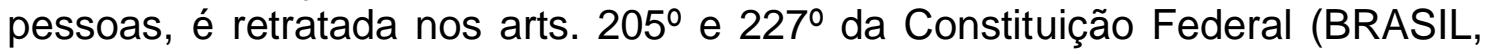
1988). O art. $205^{\circ}$ expressa que a educação visa o "pleno desenvolvimento da pessoa, seu preparo para o exercício da cidadania e sua qualificação para o trabalho". E no art. $227^{\circ}$, salienta-se a "absoluta prioridade" à criança, ao adolescente e ao jovem, a inúmeros direitos, incluindo-se o direito à educação e à profissionalização.

No que concerne à educação profissional técnica de nível médio, abordagem dada pela nova LDB - Lei no 9.394/96 -, visando tornar mais explícito o seu funcionamento, alguns de seus artigos passaram por reformulação e/ou adequação. Os principais documentos nesse sentido são: o

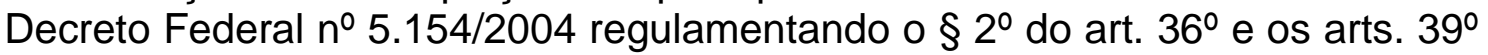
ao 41; também a Lei no 11.741/2008, alterando alguns dispositivos da Lei para redimensionar, institucionalizar e integrar as ações da educação profissional técnica de nível médio, da educação de jovens e adultos e da educação profissional e tecnológica; e ainda a Resolução do Conselho Nacional de Educação/Câmara de Educação Básica (CNE/CEB) nº 06/2012, definindo Diretrizes Curriculares Nacionais para a Educação Profissional Técnica de Nível Médio.

A Lei no 13.005/2014, responsável pela aprovação do Plano Nacional de Educação (PNE), com vigência para o decênio compreendido entre 2014 a 2024, também aborda essa modalidade de ensino por meio da meta $11 \mathrm{e}$ várias estratégias a ela vinculadas. O seu objetivo principal consiste em triplicar o número de matrículas, "assegurando a qualidade da oferta e pelo menos 50\% (cinquenta por cento) da expansão no segmento público” (BRASIL, 2014).

\section{METODOLOGIA}

A partir da análise da legislação nacional da educação profissional técnica de nível médio, buscou-se identificar a legislação que regulamenta 0 Curso Técnico de Meio Ambiente no Estado do Paraná, assim como as suas formas de oferta. O referido Curso foi selecionado tendo em vista a relevância das questões ambientais, conforme evidenciado anteriormente. 
Após a identificação, realizada por meio de pesquisa documental no site institucional da Secretaria Estadual do Estado da Educação do Paraná (SEED), a ênfase se deu na forma Integrada ao Ensino Médio, identificando se a mesma atende aos requisitos da educação politécnica, articulando os conhecimentos de cunho científicos com os da qualificação profissional, conforme os pressupostos que fundamentam o artigo. Para tanto, o principal documento analisado foi a Matriz Curricular do Curso.

A pesquisa documental, segundo Gil (2017, p. 4), utiliza-se dos mais diversos tipos de documentos produzidos com distintas finalidades. $\mathrm{Na}$ atualidade, a utilização de documentos eletrônicos em pesquisas tem se tornado comum, sendo que os de origem institucional encontram-se entre os mais utilizados.

Salienta-se que a oferta de cursos de educação profissional técnica de nível médio se ampara no Catálogo Nacional de Cursos Técnicos (CNCT). Este documento apresenta a relação de 227 cursos agrupados em 13 eixos tecnológicos, contendo orientações para subsidiar a organização e planejamento dos cursos, além de informações de cunho geral para os estabelecimentos de ensino, estudantes e comunidade escolar.

O Curso Técnico em Meio Ambiente é um dos cursos que integram o eixo tecnológico intitulado "Ambiente e Saúde", compreendendo

[...] tecnologias associadas à melhoria da qualidade de vida, à preservação e utilização da natureza, desenvolvimento e inovação do aparato tecnológico de suporte e atenção à saúde. Abrange ações de proteção e preservação dos seres vivos e dos recursos ambientais, da segurança de pessoas e comunidades, do controle e avaliação de risco, programas de educação ambiental [...] (CATÁLOGO NACIONAL DE CURSOS TÉCNICOS, 2016, p. 14).

\section{RESULTADOS E DISCUSSÕES}

De acordo com dados disponibilizados no site da SEED, são ofertados 60 cursos técnicos na Rede Estadual, entre os quais se inclui o Técnico em Meio Ambiente, ofertado em 22 instituições localizadas em 19 municípios ${ }^{4}$.

Os cursos são ofertados de formas distintas e o público a que se destinam, assim como o tempo de duração, tem relação com o nível de escolaridade apresentado pelos estudantes no ato da matrícula, conforme se demonstra no Quadro 1.

\footnotetext{
${ }^{4}$ No Paraná o Curso Técnico em Meio Ambiente é ofertado nos seguintes municípios: Almirante Tamandaré; Antonina; Apucarana; Assaí; Bela Vista do Paraíso; Cambará; Cascavel; Castro; Curitiba; Fazenda Rio Grande; Francisco Beltrão; Guarapuava; Londrina; Maringá; Pinhais; Planalto; Ponta Grossa; São Mateus do Sul; e União da Vitória. Todos os munícipios possuem uma única instituição ofertando o referido Curso, exceto Curitiba, com quatro instituições.
} 
Quadro 1 - Formas de Oferta de Cursos Técnicos de Nível Médio

\begin{tabular}{|c|c|c|}
\hline FORMA DE OFERTA & PÚBLICO-ALVO & DURAÇÃO \\
\hline $\begin{array}{c}\text { CONCOMITANTE } \\
\text { Disciplinas de formação específica }\end{array}$ & $\begin{array}{l}\text { Alunos matriculados a partir do } \\
2^{0} \text { ano do Ensino Médio }\end{array}$ & 1 a 2 anos \\
\hline $\begin{array}{c}\text { INTEGRADA } \\
\text { Disciplinas da Educação Básica e } \\
\text { da formação específica }\end{array}$ & $\begin{array}{l}\text { Concluintes do Ensino } \\
\text { Fundamental } \\
\left.\text { (9ª ano/8 }{ }^{\text {a }} \text { série }\right)\end{array}$ & 3 a 4 anos \\
\hline $\begin{array}{c}\text { PROEJA } \\
\text { Disciplinas da Educação Básica e } \\
\text { da formação específica }\end{array}$ & $\begin{array}{c}\text { Concluintes do Ensino } \\
\text { Fundamental com idade acima } \\
\text { de } 18 \text { anos } \\
\left.\text { (9º ano/ } 8^{\text {a }} \text { série }\right)\end{array}$ & $\begin{array}{c}6 \\
\text { semestres }\end{array}$ \\
\hline $\begin{array}{c}\text { SUBSEQUENTE } \\
\text { Disciplinas de formação específica }\end{array}$ & Concluintes do Ensino Médio & $\begin{array}{c}2 \text { a } 4 \\
\text { semestres }\end{array}$ \\
\hline
\end{tabular}

Fonte: SECRETARIA DO ESTADO DA EDUCAÇÃO DO PARANÁ (2019)

Mesmo verificando-se várias formas de oferta do Curso, ressalta-se a forma Integrada ao Ensino Médio. Sendo assim, por meio da análise da Matriz Curricular do Curso de Meio Ambiente Integrado ao Ensino Médio elaborada pela SEED, observa-se que as disciplinas da formação específica se encontram distribuídas ao longo dos quatro anos de duração do Curso. Essas disciplinas não se concentram, portanto, em único ano ao final do mesmo, nos moldes do modelo "3 mais 1", isto é, três anos destinados para a formação geral e mais um para a formação específica, após a conclusão do Ensino Médio, conforme organizado anteriormente. ${ }^{5}$

A forma Integrada pressupõe a articulação entre os conteúdos de formação geral e específica, considerados essenciais para a compreensão dos processos produtivos e da realidade mais ampla, conforme salientam Ciavatta e Ramos

Os conhecimentos específicos de uma profissão - mesmo ampliados para uma área profissional ou um eixo tecnológico - não são suficientes para proporcionar a compreensão das relações sociais de produção. Por isto a defesa da integração desses conhecimentos com os de formação geral. Mesmo que os processos produtivos em que se pode exercer uma profissão sejam particularidades da

5 Ao reportarem-se ao Curso Técnico em Meio Ambiente Integrado ao Ensino Médio no Colégio Estadual Paulo Leminski, localizado na cidade de Curitiba, Tomporoski e Amorim (2011, p. 6), observaram, naquele momento, a organização de três anos para a formação geral e mais um ano destinado para as disciplinas de formação específica ao final do Curso. Pode-se aferir, mediante o exposto, tal organização para os Cursos ofertados em toda a Rede Estadual de Ensino. 
realidade mais ampla, é possível estudá-los em múltiplas dimensões - econômica, social, política, cultural e técnica, dentre outras - de forma que, além dos conhecimentos específicos, os de formação geral tornam-se também uma necessidade (CIAVATTA; RAMOS, 2012, p. 26).

A Matriz Curricular do Curso Técnico em Meio Ambiente analisada apresenta oito disciplinas para a formação específica, sendo que algumas delas se repetem em mais de uma série, mais o Estágio Supervisionado, de acordo com o Quadro 2.

\section{Quadro 2 - Disciplinas Específicas para o Curso Técnico em Meio Ambiente Integrado ao Ensino Médio}

\begin{tabular}{|c|l|}
\hline SÉRIE & \multicolumn{1}{|c|}{ DISCIPLINAS ESPECíFICAS } \\
\hline $\mathbf{1}^{\mathbf{a}}$ & $\begin{array}{l}\text { Educação Ambiental; Gestão de Recursos Naturais; Legislação e } \\
\text { Segurança ambiental; e Informática Aplicada. }\end{array}$ \\
\hline $\mathbf{2}^{\mathbf{a}}$ & $\begin{array}{l}\text { Análise, Controle e Química ambiental; Gestão de Recursos Naturais; e } \\
\text { Legislação e Segurança ambiental. }\end{array}$ \\
\hline $\mathbf{3}^{\mathbf{a}}$ & $\begin{array}{l}\text { Análise, Controle e Química ambiental; Gestão de Recursos Naturais; } \\
\text { Gestão de Resíduos; e Estágio Supervisionado. }\end{array}$ \\
\hline $\mathbf{4}^{\mathbf{a}}$ & $\begin{array}{l}\text { Análise, Controle e Química ambiental; Gestão de Resíduos; Sistemas de } \\
\text { Gestão Ambiental; Metodologia Científica e Comunicação; e Estágio } \\
\text { Supervisionado. }\end{array}$ \\
\hline
\end{tabular}

Fonte: Autoria própria (2019) com base na Matriz Curricular do Curso Técnico em Meio Ambiente Integrado ao Ensino Médio da SEED (2019)

No Estado do Paraná, o Curso encontra-se fundamentado na LDB oo 9394/1996, e Decreto Federal o 5154/2004, já mencionados anteriormente; Resolução no 04/1999 - CNE, responsável por instituir as Diretrizes Curriculares Nacionais para a Educação Profissional de Nível Técnico; Parecer no 16/1999 - CNE; Resolução oo 06/2012 - CNE; Parecer no 11/2012 - CNE; e nas Deliberações no 09/2006 e 05/2013 do Conselho Estadual de Educação (CEE).

O parágrafo único, do art. 1ำ da Resolução no 04/1999 do CNE, retrata a integração da educação profissional "às diferentes formas de educação, ao trabalho, à ciência e à tecnologia, objetiva garantir ao cidadão o direito ao permanente desenvolvimento de aptidões para a vida produtiva e social" (BRASIL: Ministério da Educação - Conselho Nacional de Educação, 1999). "Meio Ambiente" é considerado na Resolução enquanto uma das áreas profissionais, caracterizada por compreender 
[...] ações de preservação dos recursos naturais, com controle e avaliação dos fatores que causam impacto nos ciclos de matéria e energia, diminuindo os efeitos causados na natureza (solo, água e ar). Compreende, igualmente, atividades de prevenção da poluição por meio da educação ambiental não escolar, da tecnologia ambiental e da gestão ambiental (BRASIL: Ministério da Educação - Conselho Nacional de Educação, 1999).

A Resolução também apresenta as competências profissionais gerais para o técnico formado na área. Já as competências específicas da habilitação profissional deverão ser definidas pelas instituições escolares de modo a completar o currículo. A exigência mínima para a habilitação corresponde a carga horária de 800 horas.

O Parecer no 16/1999 trata das Diretrizes Curriculares Nacionais para a Educação Profissional de Nível Técnico, abordando a exigência de uma educação profissional "mais ampla e polivalente" em que o profissional formado, ou seja, o técnico, "tenha um perfil de qualificação que lhe permita construir itinerários profissionais, com mobilidade, ao longo se sua vida produtiva". Para tanto, o Parecer salienta a rearticulação entre o Ensino Médio e a Educação Profissional, "eliminando uma pseudo-integração que nem preparava para a continuidade de estudos nem para o mercado de trabalho" em referência a LDB anterior (BRASIL: Ministério da Educação - Conselho Nacional de Educação, Parecer no04/1999).

Outro documento que regulamenta o Curso Técnico em Meio Ambiente no Estado diz respeito à Resolução oㅡ 06/2012 do CNE, definindo propriamente as Diretrizes Curriculares Nacionais para a Educação Profissional Técnica de Nível Médio; e o Parecer № 11/2012 a ela correspondente. No art. 5o da Resolução apresenta-se como finalidade dos cursos "proporcionar ao estudante conhecimentos, saberes e competências profissionais necessários ao exercício profissional e da cidadania, com base nos fundamentos científicotecnológicos, sócio-históricos e culturais" (BRASIL: Ministério da Educação Conselho Nacional de Educação, Resolução № 06/202012). Essas Diretrizes tornaram-se obrigatórias a partir do início do ano de 2013.

No âmbito estadual, a regulamentação do Curso ocorre pelas Deliberações no 09/2006 e 05/2013 do CEE. A Deliberação no 09/2006 apresenta normas complementares às Diretrizes Curriculares Nacionais da Educação Profissional Técnica de Nível Médio e de Especialização Técnica de Nível Médio; e a Deliberação no 05/2013 dispõe sobre as suas normas, sendo possível observar no parágrafo único, do art. 6ํㅡ, a explicitação do que se refere à articulação da Educação Profissional ao Ensino Médio

A articulação é o mecanismo pelo qual se buscará a unidade entre as dimensões trabalho, ciência, tecnologia e cultura, como forma de garantir uma identidade unitária de curso, e se expressará na relação entre o Ensino Médio e a qualificação para o trabalho; na interdisciplinaridade; na relação entre a teoria e a prática; na integração entre saberes necessários à produção do conhecimento, à intervenção social e à participação no desenvolvimento socioeconômico ambiental, devendo constar no plano de curso e no 
Projeto Político-Pedagógico da instituição de ensino (PARANÁ: Secretaria de Estado da Educação - Conselho Estadual de Educação, Deliberação $n^{0}$ 05/2013).

A integração entre Ensino Médio e a qualificação profissional observada nos documentos que integram a legislação educacional analisada, apresentam os pressupostos requeridos por uma educação politécnica. No caso do Curso Técnico em Meio Ambiente Integrado, destaca-se ainda a formação com vistas à atuação no processo produtivo com práticas ambientalmente sustentáveis, atendendo a legislação educacional e ambiental que tratam da sua obrigatoriedade.

\section{CONSIDERAÇÕES FINAIS}

Partindo-se da premissa que os cursos técnicos integrados ao Ensino Médio podem constituir-se na "gênese" para uma educação politécnica (MOURA, et al., 2015; SAVIANI, 2007), sendo capazes de fazer a "travessia" para uma nova realidade (FRIGOTTO, et al., 2005), demonstra-se a relevância que apresentam para uma formação mais humana e integral dos jovens brasileiros.

A análise da legislação educacional que regulamenta o Curso Técnico em Meio Ambiente de forma Integrada ao Ensino Médio no Estado do Paraná, ressalta a articulação entre as disciplinas da formação geral com as da formação específica, pressupondo a qualificação dos estudantes para sua inserção nos processos produtivos, ao mesmo tempo em que promove a aquisição do conhecimento técnico-científico.

Torna-se perceptível a possibilidade do técnico, além das particularidades relativas às necessidades da proteção ambiental adquiridas ao longo da formação, reconhecer a problemática socioambiental a partir de uma visão sistêmica, ou seja, no que tange aos seus aspectos políticos, culturais, econômicos e tecnológicos, sendo capaz de interferir de maneira consciente e crítica no meio em que vive.

Conhecimento técnico-científico e para a vida, associado à qualificação profissional que objetiva, antes de qualquer coisa, a manutenção da sobrevivência e a satisfação das necessidades materiais dependentes primordialmente do trabalho, são possibilidades preconizadas pelo Curso. Desse modo, a transformação da realidade, com vistas à estruturação de uma sociedade mais justa, humana, ambientalmente sustentável e igualitária para todos, pode ser considerada uma atribuição para os jovens formados no Curso Técnico em Meio Ambiente Integrado ao Ensino Médio. 


\section{REFERÊNCIAS}

BRASIL. Lei de Diretrizes e Bases da Educação Nacional. 5.692 de 11 de gosto de 1971. Subchefia para Assuntos Jurídicos Casa Civil. Disponível em: <http://www.planalto.gov.br/ccivil_03/leis/L5692.html>. Acesso em: 11 mai. 2019.

Política Nacional de Meio Ambiente. 6.938 de 31 de agosto de 1981. Subchefia para Assuntos Jurídicos Casa Civil. Disponível em: <http://www.planalto.gov.br/ccivil_03/leis//6938.htm>. Acesso em: 28 de mai. 2019.

. Constituição da República Federativa do Brasil. Brasília: Centro Gráfico, 1988. 292 p.

Lei de Diretrizes e Bases da Educação Nacional. 9.394 de 20 de dezembro de 1996. Subchefia para Assuntos Jurídicos Casa Civil. Disponível em: <http://www.planalto.gov.br/ccivil_03/LEIS/19394.htm>. Acesso em: 28 mai. 2019.

. Secretaria de Educação Fundamental. Parâmetros curriculares nacionais: apresentação dos temas transversais, ética / Secretaria de Educação Fundamental. Brasília: MEC/SEF, 1997.

. Política Nacional de Educação Ambiental. 9.795 de 27 de abril de 1999. Subchefia para Assuntos Jurídicos Casa Civil. Disponível em: $<$ http://www.planalto.gov.br/ccivil_03/Leis/L9795.htm>. Acesso em: 08 mai. 2019.

. Ministério da Educação. Conselho Nacional de Educação. Resolução no 04 de 05 de outubro de 1999. Disponível em: < http://portal.mec.gov.br/setec/arquivos/pdf/RCNE_CEB04_99.pdf >. Acesso: em 10 de jun. 2019.

. Ministério da Educação. Conselho Nacional de Educação. Parecer no 16 de 05 de outubro de 1999. Disponível em:

$<$ http://portal.mec.gov.br/setec/arquivos/pdf_legislacao/rede/legisla_rede_parec er1699.pdf>. Acesso em: 10 de jun. 2019.

. Ministério da Educação. Conselho Nacional de Educação. Parecer no 06 de 20 de setembro de 2012. Disponível em:

$<$ http://portal.mec.gov.br/index.php?option=com_docman\&view=download\&alia $\mathrm{s}=11663$-rceb006-12-pdf\&category_slug=setembro-2012-pdf\&Itemid=30192>. Acesso em: 10 de jun. 2019.

. Ministério da Educação. Conselho Nacional de Educação. Parecer no 11 de 09 de maio de 2012. Disponível em:

$<$ http://portal.mec.gov.br/index.php?option=com_docman\&view=download\&alia $s=10804-p c e b 011-12$-pdf\&ltemid=30192 >. Acesso em: 10 de jun. 2019. 
Plano Nacional de Educação. 13.005 de 25 de junho de 2014.

Subchefia para Assuntos Jurídicos Casa Civil. Disponível em:

<http://www.planalto.gov.br/ccivil_03/_ato2011-2014/2014/lei/l13005.htm>.

Acesso em 08 mai. 2019.

Catálogo Nacional de Cursos Técnicos. Ministério da Educação,

2016.Disponível em:

$<$ http://portal.mec.gov.br/index.php?option=com_docman\&view=download\&alia $\mathrm{s}=77451$-cnct-3a-edicao-pdf-1\&category_slug=novembro-2017-

pdf\&Itemid=30192>. Acesso em: 08 de mai. 2019.

BRUNACCI, A.; PHILIPPI Jr, A. A Dimensão Humana do Desenvolvimento Sustentável. In: Educação Ambiental e Sustentabilidade. PHILLIPPI Jr, A.; PELICIONI, M. C. F. (Ed.) 2. ed. São Paulo: Manole, 2014. Coleção Ambiental, v. 14. P. 307-333.

CARSON, Rachel. Primavera Silenciosa. São Paulo: Gaia, 2010.

CARVALHO, M. G. Tecnologia e Sociedade. In: BASTOS, J. A. Tecnologia \& Interação. Curitiba: CEFET/PR, 1998. Cap. 5.

CIAVATTA, Maria; RAMOS, Marise. A "era das diretrizes": a disputa pelo projeto de educação dos mais pobres. Revista Brasileira de Educação, Rio De Janeiro, v. 17, n. 49, p.11-36, jan/abr. 2012.

ENGUITA, Mariano Fernández. A face oculta da escola: educação e trabalho no capitalismo. Porto Alegre: Artes Médicas, 1989. Cap. 8.

FAZENDA, Ivani C. Integração e interdisciplinaridade no ensino brasileiro: efetividade ou ideologia. 6. ed. São Paulo: Edições Loyola, 2011.

FRIGOTTO, Gaudêncio; CIAVATTA. Maria; RAMOS, Marise. A gênese do Decreto N. 5.154/2004. Um debate no contexto controverso da democracia restrita. Trabalho Necessário, 2005. p. 1-26.

GIL, Antonio Carlos. Como elaborar projetos de pesquisa. 6. ed. São Paulo: Atlas, 2017.

GUIMARÃES, Mauro. A formação de educadores ambientais. 8. ed. São Paulo: Papirus, 2012.

2015.

. A dimensão ambiental na educação. 12. Ed. São Paulo: Papirus,

MOURA, Dante Henrique; LIMA FILHO, Domingos Leite; SILVA, Mônica Ribeiro. Politecnia e formação integrada: confrontos conceituais, projetos políticos e contradições históricas da educação brasileira. In: Revista

Brasileira de Educação. Dez 2015, vol. 20, nํ63, p. 1057-1080. 
PARANÁ. Secretaria de Estado da Educação. Onde Cursar Cursos Técnicos. Eixos: Ambiente e Saúde. Disponível em: $<$ http://www.comunidade.diaadia.pr.gov.br/modules/conteudo/conteudo.php?co nteudo=39\#meio_ambiente $>$. Acesso em: 11 de mai. 2019.

\section{Secretaria de Estado da Educação. Matriz Curricular do Curso}

Técnico em Meio Ambiente Integrado. Disponível em:

$<$ http://www.educadores.diaadia.pr.gov.br/arquivos/File/educacao_profissional/ meio_ambiente_integrado.pdf >. Acesso em: 11 de mai. 2019.

. Secretaria do Estado da Educação. Conselho Estadual de Educação.

Deliberação no 09 de 20 de dezembro de 2006. Disponível em:

<http://www.cee.pr.gov.br/arquivos/File/pdf/Deliberacoes/2006/deliberacao_09_ 06.pdf>. Acesso em: 13 de jun. 2019.

Secretaria de Estado da Educação. Conselho Estadual de Educação.

Deliberação no 05 de 10 de dezembro de 2013. Disponível em:

$<$ http://www.cee.pr.gov.br/arquivos/File/pdf/Deliberacoes/2013/deliberacao_05_ 13.pdf>. Acesso em: 13 de jun. 2019.

PESAVENTO, Sandra Jatahy. Exposições Universais: espetáculos da modernidade do século XIX. São Paulo: Hucitec, 1997, p. 42-55.

RODRIGUES, Ana Paula da Silva. Análise da Aplicação das Diretrizes Públicas de Educação Ambiental em Área de Mananciais: Estudo de Caso do Município de Piraquara/PR. 2018. 210 f. Dissertação (Mestrado em Tecnologia e Sociedade) - Programa de Pós-Graduação em Tecnologia e Sociedade, Universidade Tecnológica Federal do Paraná. Curitiba, 2018.

SANTOS, Laymert Garcia dos. Politizar as novas tecnologias. São Paulo: Cia das Letras, 2000. p. 15-48.

SAVIANI, Dermeval. Trabalho e educação: fundamentos ontológicos e históricos. Revista Brasileira de Educação. 2007, vol. 12, n. 34, p. 152-165.

TOMPOROSKI, Avani; AMORIM, Mario. A Formação no Ensino Médio Técnico no Panará - O Curso Técnico em Meio Ambiente. In: IV Simpósio Nacional de Tecnologia e Sociedade. Anais. Curitiba, 2011. Disponível em: $<$ http://www.esocite.org.br/eventos/tecsoc2011/cdanais/arquivos/pdfs/artigos/gt028-aformacao.pdf>. Acesso em 13 de jun. 2019. 